\title{
Eğirdir Gölü kerevitlerinde (Astacus leptodactylus, Eschscholtz, 1823) büyüme ve üreme özelliklerinin belirlenmesi*
}

\author{
Yıldız BOLAT ${ }^{1 * *}$, Mehmet Ali KAYA ${ }^{2}$
}

${ }^{1}$ Süleyman Demirel Üniversitesi Eğirdir Su Ürünleri Fakültesi - Isparta

${ }^{2}$ Eğirdir Su Ürünleri Araştırma Enstitüsü Müdürlüğü Eğirdir - Isparta

Geliş : $\quad 01.10 .2015$

Kabul : $\quad 08.02 .2016$

**Sorumlu Yazar: yldzbolat@sdu.edu.tr

Bas1lı ISSN: 1300 - 4891E. Dergi ISSN: 1308 - 7517

\section{Özet}

Bu çalışma Haziran 2013 ile Haziran 2014 tarihleri arasında Eğirdir Gölü'nde yürütülmüştür. Araştırmada, Eğirdir Gölü kerevitlerinin boy, ağırlık ve eşey kompozisyonu, boy-ağırlık ilişkisi, av verimliliği, kabuk değiştirme mevsimi, üreme dönemi ve yumurta verimliliği belirlenmiştir. Toplam 3008 adet kerevit avlanmış olup, bunların 2456'sı incelenmiştir. Kerevitlerin total boy ortalaması $106,31 \mathrm{~mm}$, canlı ağırlık ortalaması ise 40,33 g olarak hesaplanmıştır. Boy-ağırlık ilişkisinde regresyon denklemi Log $\mathrm{W}=-3,2648+2,7918 \mathrm{x} \log \mathrm{CL}$, regrasyon katsayısı $\mathrm{r}^{2}=0,9016$ olarak bulunmuştur. Deneme sonunda, hem erkek hem de dişi bireylerde negatif allometrik büyümenin olduğu saptanmıştır. Populasyondaki dişi/erkek oranı ise $0,75 / 1,00$ olarak belirlenmiştir. Ortalama yumurta sayısı 309 ortalama yumurta çapı ise 2,53 mm olarak hesaplanmıştır.

Anahtar kelimeler: Kerevit, Astacus leptodactylus, Büyüme, Üreme, Eğirdir Gölü, Türkiye

Determination of growth and reproduction properties of freshwater crayfish (Astacus leptodactylus, Eschscholtz, 1823) in Eğirdir Lake-Türkiye

\begin{abstract}
This Study was carried out between June 2013 and June 2014 in Eğirdir Lake. The length, weight, sex composition, length-weight relationship, catch efficiency, moulting season, reproductive period and fecundity of crayfish were determined in Eğirdir Lake. In this study, total 3008 crayfish were caught and 2456 of those crayfish were determined as $106.31 \mathrm{~mm}$ and $40.33 \mathrm{~g}$, respectively. Regression equation of length-weight relationship was found as $\log \mathrm{W}=-3.2648+2.7918 \mathrm{x} \log \mathrm{CL}$ and regression coefficient was determined as $\mathrm{r}^{2}=0.9016$. It was found to be negative allometric growth in both males and females. The female-male ratio of population was determined as $0.75 / 1.00$. The mean egg number and egg diameter were determined as 309 and $2.53 \mathrm{~mm}$ respectively.
\end{abstract}

Keywords: Crayfish, Astacus leptodactylus, Growth, Reproduction, Eğirdir Lake, Türkiye

*Bu çalışma yüksek lisans tezinden özetlenmiştir.

\section{GíRIŞ}

Türkiye'nin doğal tatlı su istakozu türü olan A. leptodactylus, özellikle Anadolu dışında da geniş bir dağılım alanı olması ve ekonomik önemi bulunması nedeniyle Avrupa'nın en popüler türlerinden biridir (Köksal, 1988).

Kerevitler doğal olarak bulundukları tatlı su alanlarında ekolojik dengenin birer parçası halindedirler. Beslenme özellikleri bakımından omnivor olduklarından su kaynaklarındaki pek çok organizmayı tüketebilirler (Huner, 1994). Ayrıca, her türlü organik materyalin işlenmesinde oynadıkları önemli rol nedeni ile ekosistemde enerji dengeleri üzerinde etkindirler (Hessen vd., 1993; Wallace vd., 1997; Zhang vd., 2003). Ayrışmakta olan materyaller üzerinden beslenen, detritusun işlenmesi ve mineralizasyonunda, bentik 
çeşitlilik ve organik madde birikiminde önemli etkileri bulunan bu canlılar için "ekosistem mühendisi" benzetmesi yapılmaktadır (Zhang vd., 2004).

Kerevitler ekosistemde oynadıkları bu roller nedeni ile durgun ve akarsu habitatları için anahtar tür olarak görülmektedirler (Hogger, 1988; Momot, 1995; Nyström, 2002). Ortamdan yok olmaları veya yeni bir ortama sokulmaları sucul ekosistemler üzerinde çok ciddi etkiler doğurabilir (Matthews ve Reynolds, 1992; Nyström ve Strand, 1996).

Populasyonların korunması ve sürdürülebilir avcılık için kerevitlerin populasyondaki büyüme ve üreme özelliklerinin belirlenmesi gerekmektedir. Bu çalışmadan elde edilecek bilgiler Eğirdir Gölü’nde yıllara bağlı olarak meydana gelebilecek değişikliklerin izlenmesi ve karşılaştırılmasında hatta avlanma stratejilerinin planlanmasında faydalı olacaktır. Bu amaçla, Eğirdir Gölü'nde yaşayan kerevitlerin eşey gruplarına göre boy ve ağırlık kompozisyonu, boy-ağırlık ilişkisi, kabuk değiştirme mevsimi, av verimliliği, olgunlaşma büyüklüğü, üreme periyodu ve yumurta verimliliği belirlenmiştir.

\section{MATERYAL ve YÖNTEM}

Bu çalışma, Haziran 2013 ile Haziran 2014 tarihleri arasında Eğirdir Gölü'nde gerçekleştirilmiştir. Araştırmada, $34 \mathrm{~mm}$ göz açıklığında tek girişli, yönlendirmeli, 2 hazneli kerevit pinterleri kullanılmıştır. Örneklemeler aylık yapılmış olup 13 ay sonunda toplam 2402 adet kerevit pinteri kullanılarak 3008 adet kerevit avlanmıştır. Yakalanan kerevitlerin laboratuvarda cinsiyetleri tespit edilerek gerekli metrik ölçümleri yapılmıştır.

İncelenen kerevitlerin boy ölçümleri için $1 \mathrm{~mm}$ hassasiyetli ölçü cetveli, ağırlık ölçümleri için 0,1 g hassasiyetli tartım cihazı kullanılmıştır. Kerevitlerin boy uzunluklarını belirlemek amacıyla Total Boy (TL), Karapaks Boy (CL) ölçümleri alınarak, canlı ağırlıkları (W) tartılmıştır. Kerevitlerin dişi, erkek ve dişi+erkek olmak üzere total boy, karapaks boy ve total ağırlık ortalamaları hesaplanarak boy gruplarına ve ağırlık gruplarına göre frekans dağılımları incelenmiştir.

Populasyonun eşey kompozisyonu tespiti için boy gruplarına göre eşey dağılımı incelenerek, aylara göre dişi- erkek oranları belirlenmiştir. Eğirdir Gölü kerevitlerinin eşeylere göre boy-ağırlık ilişkisi Le Cren (1951)'in $\mathrm{W}=\mathrm{aL}^{\mathrm{b}}$ üstel ilişki modelinin Log W $=\log \mathrm{a}+\mathrm{b}$ Log L şeklindeki doğrusal denklemi kullanılarak hesaplanmıştır (Atay, 1989).

Avlanabilir boydaki bireylerin oranı, boy frekans dağılımında yasal avlanma boyu olan $10 \mathrm{~cm}$ ve üzerindeki bireylerin oranı hesaplanarak bulunmuştur.

Eğirdir Gölü kerevitlerinin kabuk değiştirme mevsimini belirlemek amacıyla eşeysel olarak aylara göre kabuk durumları makroskobik olarak kontrol edilmiştir.

Eğirdir Gölü kerevitlerinin olgunlaşma büyüklüğünün tespiti için, ovaryumlarında ve pleopodlarında yumurta bulunan dişiler ile testislerinde sperma hücreleri bulunan en küçük boya sahip erkek bireyler dikkate alınarak belirlenmiştir.

Aralık 2013 ile Haziran 2014 tarihleri arasında temin edilen 7 adet yumurtalı dişiden total boy (TL), canlı ağırlık (W) ile ortalama yumurta sayısı ve ortalama yumurta çapı hesaplanmıştır. Laboratuara getirilen yumurtalı bireylerin yumurtaları bir pens yardımıyla petri kaplarına alınarak yumurta sayıları belirlenmiştir. Kerevitlerin yumurta çapları 0,05 mm hassasiyetli kumpas yardımı ile stereo zoom mikroskop altında ölçülmüştür. 


\section{BULGULAR}

Çalışmada, yakalanan toplam 3008 adet kerevitin 1289 tanesinin $(\% 42,85)$ dişi, 1719 tanesinin $(\% 57,15)$ ise erkek olduğu belirlenmiş, dişi/erkek oranı $0,75 / 1,00$ olarak bulunmuştur. Kerevitlerin total boylarının (TL) 66-168 mm, karapaks boylarının (CL) 31$88 \mathrm{~mm}$ arasında dağılım gösterdiği tespit edilmiştir. Kerevitlerin total boy ortalama değeri $106,31 \mathrm{~mm}$, karapaks boylarının ortalaması ise 53,74 mm bulunmuştur. Kerevitlerin canl1 ağırlık değerinin 8-158,5 g arasında dağılım gösterdiği ve ortalama ağırlık değerinin 40,33 g olduğu tespit edilmiştir (Şekil 1,2,3).

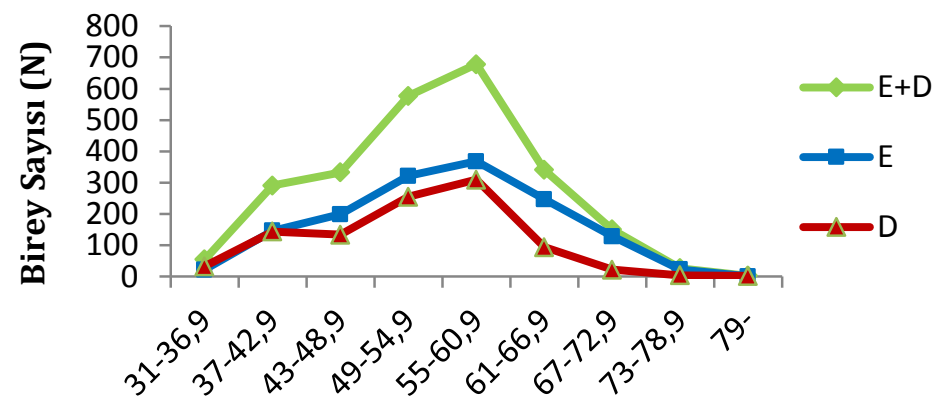

Boy Grupları (CL mm)

Şekil 1. Kerevitlerin boy gruplarına göre eşey dağılımı

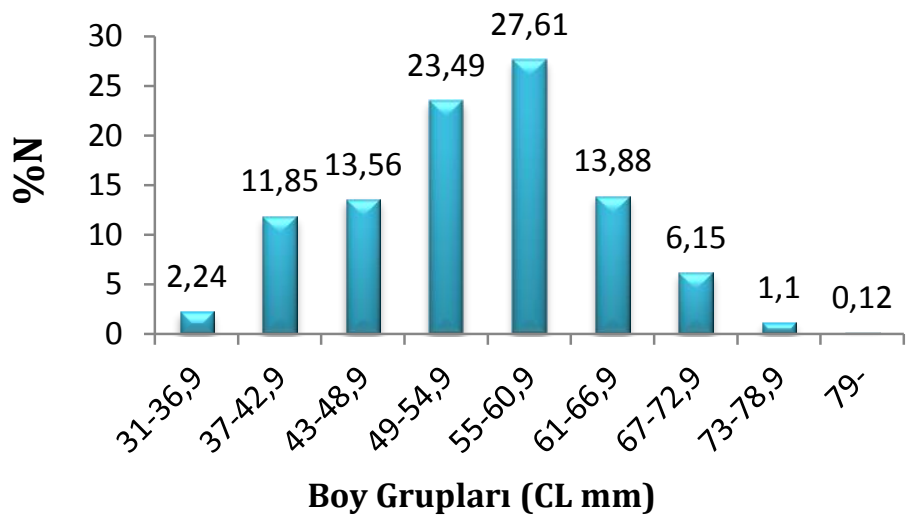

Şekil 2. Kerevitlerin boy frekans dağılımı 


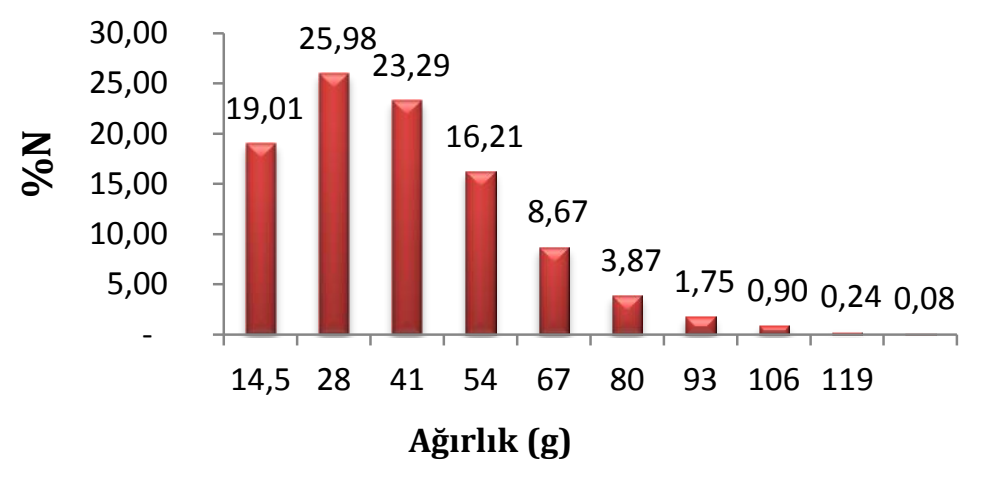

Şekil 3. Kerevitlerin ağırlık kompozisyonu

Kerevit populasyonunun boy-ağırlık ilişkisi 998 dişi, 1458 erkek toplam 2456 adet kerevitin karapaks boyu-canlı ağırlık ilişkileri linear regresyon analizi ile logaritmik olarak incelenmiş olup, regresyon denklemi erkek kerevitlerde $\log \mathrm{W}=-3,4450+2,8907 x \log \mathrm{CL}$, dişi kerevitlerde $\log \mathrm{W}=-3,0755+2,6886 x \log \mathrm{CL}$, dişi+erkek kerevitlerde Log $\mathrm{W}=-$ 3,2648+2,7918x Log CL olarak hesaplanmıştır. Eğirdir Gölü kerevitlerinde hem dişi bireylerde hem de erkek bireylerde boy ve ağırlık artışında doğrusal bir ilişki olduğu tespit edilmiştir (erkek $r=0,91$, dişi $r=0,89$, dişi+erkek $r=0,90$ ). Regresyon denklemlerinde " $\mathrm{b}$ " değeri hem dişi hem de erkek bireylerde 3'ün altında olduğu ve kerevitlerin negatif allometrik büyüme gösterdiği bulunmuştur (dişi $b=2,6886$, erkek $b=2,8907$, dişi-erkek $\mathrm{b}=2,7918)$ (Şekil 4,5,6).

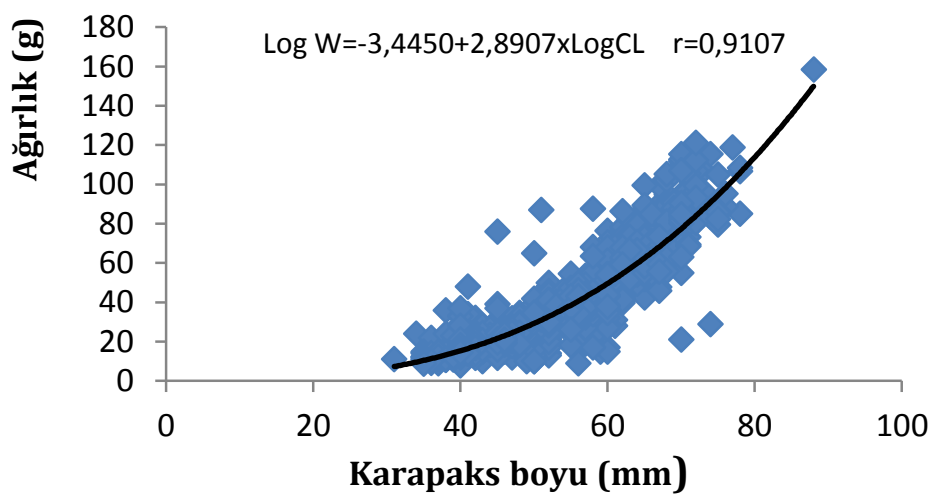

Şekil 4. Erkek Astacus leptodactylus populasyonunda karapaks boy-ağırlık ilişkisi 


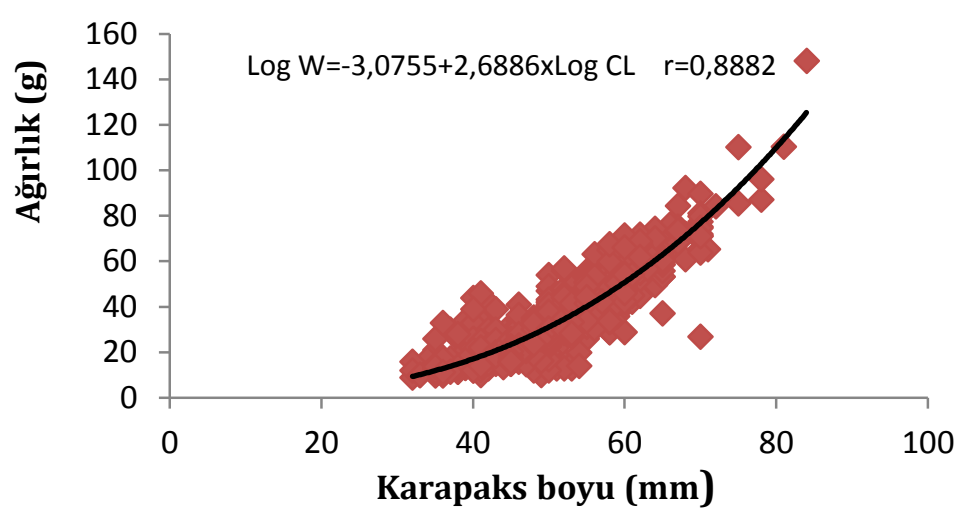

Şekil 5. Dişi Astacus leptodactylus populasyonunda karapaks boy-ağırlık ilişkisi

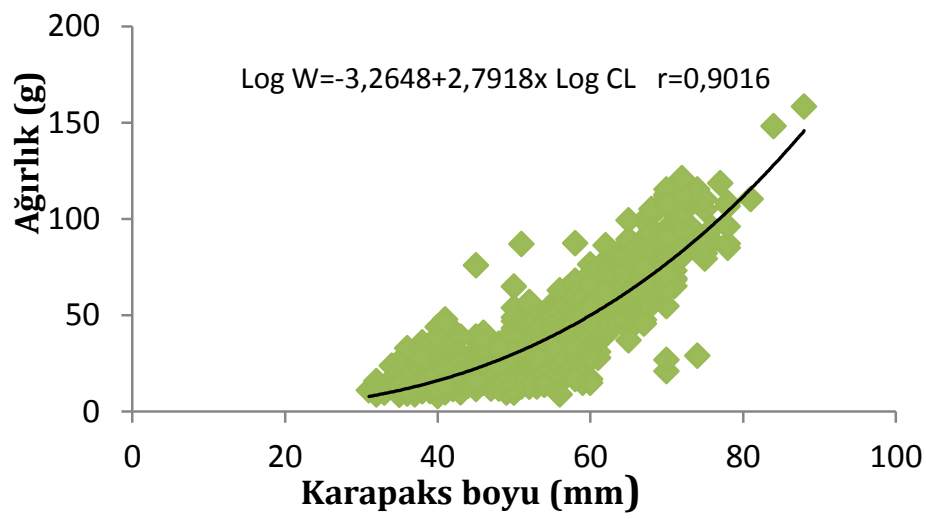

Şekil 6. Erkek ve dişi Astacus leptodactylus populasyonunda karapaks boy ağırlık ilişkisi

Eğirdir Gölü'nde avlanabilir boyun üzerindeki erkek bireylerin 31-88 mm, dişi kerevitlerin 32-84 mm karapaks boy gruplarında dağılım gösterdiği ve örnek populasyonun \%68,04'ünün avlanabilir boyun üzerinde olduğu bulunmuştur.

Eğirdir Gölü kerevitlerinin kabuk değiştirme mevsimi aylara göre eşeysel olarak incelenmiş olup dişi bireylerin Haziran-Kasım ayları arasında erkek bireylerin MayısKasım ayları arasında dişi+erkek bireylerin Ağustos-Eylül ayları arasında yoğun olarak kabuk değiştirdikleri tespit edilmiştir.

Eğirdir Gölü kerevitlerinin olgunlaşma büyüklüğünün tespiti için ovaryumlarında ve pleopodlarında yumurta bulunan dişiler ile testislerinde sperma hücresi bulunan en küçük boya sahip bireyler dikkate alınmıştır ve olgunlaşma büyüklüğü erkeklerde $74 \mathrm{~mm}$, dişi bireylerde ise $77 \mathrm{~mm}$ olarak bulunmuştur. Eğirdir Gölünde çiftleşme olayı Ekim ayının son haftası ile Kasım ayının ilk haftasında gerçekleşmiş olup dişilerin genital açıklıklarında sperma kalıntıları 4 Kasım'da gözlemlenmiştir. Çiftleşme olayından 4- 5 hafta sonra pleopodlarında yumurta taşıyan dişilere 20 Aralıkta rastlanmıştır. Yumurtalardan yavru çıkışı yaklaşık 6 aylık inkübasyon süresi sonunda Haziranın ilk haftasında gerçekleşmiştir.

Araştırma kapsamında Eğirdir Gölü kerevitlerinin yumurta verimliliğini belirlemek amacıyla dişi bireylerin yumurta sayıları sayılarak, ortalama yumurta sayısı 309 ve yumurta çapı ölçülerek, ortalama yumurta çapı 2,53 mm bulunmuştur. 


\section{TARTIŞMA ve SONUÇ}

Kerevitlerin boyca büyümeleri ancak kabuk değiştirmeleri ile olanaklıdır. Kerevitlerde genelde genç bireyler yılda $2-3 \mathrm{kez}$, yaşlı bireyler ise y1lda 1 kez kabuk değiştirmektedirler. Kerevitlerin ilk yılda 8 kez, ikinci yılda 5 kez kadar kabuk değiştirebildikleri, daha ileri yıllarda ise bu sayının 2 veya 1'e düştügü̈ bilinmektedir (Erdemli, 1985). Dişi bireyler üreme dönemi sırasında uzun süre abdomenlerinin altlarında yavrularını korurlar bu dönemde erkeklere göre daha az beslenirler ve kabuk değişimi yapmazlar (Balık vd., 2005). $\mathrm{Bu}$ nedenle yapılan çalışmalarda erkek bireylerin daha ağır ve uzun oldukları bulunmuştur (Adegboye, 1981; Harlıoğlu, 2000). Bu çalışmada incelenen erkek ve dişi kerevitlerin ağırlık ve boy ortalamaları alındığında erkeklerin dişilerden daha uzun ve ağır olduğu saptanmıştır. Erdemli (1982), Karabatak ve Tüzün (1989), Kuşat ve Bolat (1995) tarafından yapılan araştırmalarda bu saptamayla benzerlik göstermektedir (Tablo 1).

Doğal ortamlarda Astacidae familyasından olan kerevit populasyonlarının cinsiyet oranı bire çok yakındır ve çok eşlilik görülür (Reynolds vd., 1992). Bununla birlikte, erkek bireylerin birden fazla dişinin yumurtalarını dölleme yeteneklerinin olması nedeniyle hem kuluçkalanan dişi kerevit sayısını arttırmak hem de yeniden stoklamalarda ve yetiştiricilik ünitelerinde bir erkeğe karşı birden fazla dişi olması hedeflenmektedir (Berber ve Balık, 2006). Populasyonun eşey kompozisyonu incelendiğinde Kuşat ve Bolat (1995), Balık vd. (2005), Berber ve Balık (2006), Yüksel (2007) bulgularıyla benzerlik göstermiş ve populasyondaki erkeklerin $(\% 57.15)$ dişilerden $(\% 42,15)$ daha yoğun olduğu tespit edilmiştir. Populasyonun dişi erkek oranı 0,75/1,00 olarak bulunmuştur (Tablo 1).

Tablo 1. Farklı kaynaklarda boy-ağırlık ve eşey dağılımı ile ilgili yapılmış çalışmalar

\begin{tabular}{|c|c|c|c|c|c|c|c|}
\hline Çalışma & Kaynak & Eşey & $\mathbf{T B} \pm \mathbf{S H}$ & $\mathrm{TA} \pm \mathrm{SH}$ & 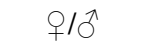 & $\%$ & $\mathbf{\%}$ ㅇ \\
\hline \multirow{2}{*}{ Köksal (1980) } & \multirow{2}{*}{ Eğirdir } & $\hat{\partial} \hat{o}$ & $101,06 \pm 1,221$ & $29,57 \pm 1,348$ & \multirow{2}{*}{$1,09 / 1,00$} & \multirow{2}{*}{47} & \multirow{2}{*}{53} \\
\hline & & 우우 & $101,17 \pm 0,980$ & $24,95 \pm 0,784$ & & & \\
\hline \multirow{2}{*}{ Erdemli (1982) } & \multirow{2}{*}{ Eğirdir } & $\hat{\sigma} \hat{\sigma}$ & $103,02 \pm 2,177$ & $32,05 \pm 2,209$ & \multirow{2}{*}{$1,56 / 1,00$} & \multirow{2}{*}{39} & \multirow{2}{*}{61} \\
\hline & & 우우 & $96,30 \pm 2,182$ & $30,65 \pm 2,201$ & & & \\
\hline \multirow{4}{*}{ Erdemli (1985) } & \multirow{2}{*}{ Hotamış } & $\sigma^{\pi}$ & $109,92 \pm 2,313$ & $35,41 \pm 2,316$ & \multirow{2}{*}{$1,00 / 1,00$} & & \\
\hline & & 우우 & $98,90 \pm 2,303$ & $32,18 \pm 2,205$ & & & \\
\hline & \multirow{2}{*}{ Mamasın } & $\widehat{\partial} \widehat{\partial}$ & $116,72 \pm 2,319$ & $42,19 \pm 2,516$ & \multirow{2}{*}{$1,00 / 1,00$} & & \\
\hline & & 우우 & $103,74 \pm 2,298$ & $35,24 \pm 2,418$ & & & \\
\hline \multirow{2}{*}{$\begin{array}{l}\text { Karabatak ve } \\
\text { Tüzün (1989) }\end{array}$} & \multirow{2}{*}{ Mogan } & $\widehat{\partial}$ & $105,44 \pm 17,30$ & $36,98 \pm 19,65$ & \multirow{2}{*}{$1,22 / 1,00$} & \multirow{2}{*}{44,9} & \multirow{2}{*}{55,1} \\
\hline & & 우우 & $104,45 \pm 17,09$ & $31,92 \pm 15,43$ & & & \\
\hline \multirow{2}{*}{$\begin{array}{l}\text { Kuşat ve Bolat } \\
\text { (1995) }\end{array}$} & \multirow{2}{*}{ Eğirdir } & $\widehat{\partial}$ & $107,21 \pm 26,12$ & $52,91 \pm 37,54$ & \multirow{2}{*}{$0,60 / 1,00$} & \multirow{2}{*}{54} & \multirow{2}{*}{46} \\
\hline & & 우우 & $92,67 \pm 22,85$ & $29,18 \pm 20,04$ & & & \\
\hline \multirow{2}{*}{ Güner (2000) } & \multirow{2}{*}{ Iş1kl1 } & $\widehat{\partial} \widehat{\partial}$ & $99,75 \pm 1,576$ & $32,88 \pm 1,689$ & \multirow{2}{*}{$1,86 / 1,00$} & & \\
\hline & & 우우 & $104,36 \pm 1,259$ & $31,72 \pm 1,114$ & & & \\
\hline \multirow{2}{*}{$\begin{array}{l}\text { Erdem vd. } \\
\text { (2001) }\end{array}$} & \multirow{2}{*}{ İznik } & के & $99,30 \pm 2,810$ & $30,99 \pm 2,320$ & \multirow{2}{*}{$0,89 / 1,00$} & & \\
\hline & & 우우 & $101,11 \pm 2,430$ & $28,59 \pm 1,578$ & & & \\
\hline \multirow{2}{*}{$\begin{array}{l}\text { Balık vd., } \\
\text { (2005) }\end{array}$} & \multirow{2}{*}{ Demirköprü } & $\widehat{\partial}$ & $90,18 \pm 0,832$ & $25,43 \pm 0,798$ & \multirow{2}{*}{$0,49 / 1,00$} & \multirow{2}{*}{67,3} & \multirow{2}{*}{32,7} \\
\hline & & 우우 & $92,88 \pm 1,041$ & $24,19 \pm 0,811$ & & & \\
\hline
\end{tabular}




\begin{tabular}{|c|c|c|c|c|c|c|c|}
\hline \multirow{6}{*}{$\begin{array}{l}\text { Harlıoğlu ve } \\
\text { Harlığlu } \\
\text { (2005) }\end{array}$} & \multirow{2}{*}{ Eğirdir } & $\widehat{\partial} \hat{0}$ & $101,81 \pm 4,15$ & $49,94 \pm 2,21$ & \multirow{2}{*}{$1,00 / 1,00$} & \multirow{2}{*}{50} & \multirow{2}{*}{50} \\
\hline & & 우우 & $103,29 \pm 7,08$ & $48,93 \pm 3,38$ & & & \\
\hline & \multirow{2}{*}{ İznik } & $\hat{\partial} \hat{O}$ & $100,47 \pm 6,70$ & $49,13 \pm 3,34$ & \multirow{2}{*}{$1,05 / 1,00$} & \multirow{2}{*}{48,8} & \multirow{2}{*}{51,2} \\
\hline & & 우우 & $104,54 \pm 7,22$ & $49,23 \pm 3,42$ & & & \\
\hline & \multirow{2}{*}{ Hirfanl1 } & $\widehat{\partial} \widehat{\partial}$ & $104,76 \pm 5,41$ & $50,59 \pm 2,26$ & \multirow{2}{*}{$0,41 / 1,00$} & \multirow{2}{*}{70,8} & \multirow{2}{*}{29,2} \\
\hline & & 우우 & $105,93 \pm 4,86$ & $50,64 \pm 2,27$ & & & \\
\hline \multirow{2}{*}{$\begin{array}{l}\text { Berber ve } \\
\text { Balık (2006) }\end{array}$} & \multirow{2}{*}{ Manyas } & $\widehat{\partial \jmath}$ & $82,12 \pm 0,559$ & $19,57 \pm 0,565$ & \multirow{2}{*}{$0,53 / 1,00$} & \multirow{2}{*}{65,4} & \multirow{2}{*}{34,6} \\
\hline & & 우우 & $89,07 \pm 1,142$ & $21,85 \pm 0,736$ & & & \\
\hline \multirow{2}{*}{ Yüksel (2007) } & \multirow{2}{*}{ Keban } & $\bar{\partial}$ & $93 \pm 0,01$ & $28,7 \pm 0,20$ & \multirow{2}{*}{$0,81 / 1,00$} & \multirow{2}{*}{55,12} & \multirow{2}{*}{44,88} \\
\hline & & 우우 & $93 \pm 0,01$ & $24,0 \pm 0,15$ & & & \\
\hline \multirow{2}{*}{$\mathrm{Bu}$ çalışma } & \multirow{2}{*}{ Eğirdir } & $\bar{\partial}$ & $106,48 \pm 0,424$ & $42,44 \pm 0,577$ & \multirow{2}{*}{$0,75 / 1,00$} & \multirow{2}{*}{57,15} & \multirow{2}{*}{42,85} \\
\hline & & 우우 & $106,07 \pm 0,519$ & $37,25 \pm 0,554$ & & & \\
\hline
\end{tabular}

Çalışmada elde ettiğimiz değerlerle geçmiş yıllarda yapılan araştırma sonuçları karşılaştırıldığında boy, ağırlık ve eşey kompozisyon değerleri bakımından benzerlikler olduğu gibi farklılıkların da olduğu gözlenmiştir. Bu konudaki farklılıkların oluşmasına, kerevitlerin çiftleşme, yumurtlama, kabuk değiştirme dönemlerinde avlanması, populasyon üzerindeki av baskısı ve çalışmada kullanılan av aracı gibi kriterlerin etkili olduğu düşünülmektedir.

Araştırmamızda Eğirdir Gölü erkek kerevitleri 31-88, dişileri ise 32-84 mm karapaks boy gruplarında dağılım göstermişler ve populasyonun \%68,04'ü avlanabilir boyun üzerinde tespit edilmiştir.

Türkiye'de farklı bölgelerde yapılan çalışmalarda, Eğirdir Gölü'nde örnek populasyonun \%36,56'sı (Anonymous, 1980), Hotamış Gölü’nde \%73’ü, Mamasın Baraj Gölü’nde \%75'i (Erdemli, 1985), Mogan Gölü’nde 60,23’ü (Karabatak ve Tüzün, 1989), Keban Baraj Gölü'nde \%73,83'ü (Duman ve Pala, 1998), Eğirdir Gölü'nde \%73,83'ü (Bolat, 2001), Dikilitaş Göleti'nde (Köksal vd., 2003) \%77,38'i, Sera Gölü'nde (Erkebay, 2004) \%66,05’i, Manyas Gölü'nde (Berber ve Balık, 2006) \%27,82, Keban Baraj Gölü'nde (Yüksel, 2007) \%64,4 avlanabilir boyun üzerinde çıkmıştır (Tablo 2).

Ülkemizde kerevitlerin yasal av boyu 2/1 Numaralı Ticari Amaçlı Su Ürünleri Avcılığını Düzenleyen Tebliğe göre 2008 yılında $10 \mathrm{~cm}$ olarak belirlenmiştir. Eğirdir Gölünde avlanabilir boyun üzerindeki bireylerin toplam populasyon içerisinde \%68,04 oranı ile yüksek bulunduğu ve düzenlemenin yerinde bir karar olduğu düşünülmektedir.

Tablo 2. Farklı çalışmalarda avlanabilir boyun üzerindeki kerevit miktarı

\begin{tabular}{ccc}
\hline \hline Araştırmacı & Kaynak & Avlanabilir kerevit (\%) \\
\hline Anonymous, 1980 & Eğirdir Gölü & $\% 36,56$ \\
Erdemli, 1982 & Eğirdir Gölü & $\% 64,66$ \\
Erdemli, 1985 & Hotamış Gölü & $\% 73$ \\
& Mamasın B. Gölü & $\% 75$ \\
Karabatak ve Tüzün, 1989 & Mogan Gölü & $\% 60,23$ \\
Bolat, 1996 & Eğirdir Gölü & $\% 65,13$ \\
Bolat, 2001 & Eğirdir Gölü & $\% 73,8$
\end{tabular}




\begin{tabular}{ccc} 
Erkebay, 2004 & Sera Gölü & $\% 77,38$ \\
Balık vd., 2005 & Demirköprü B. G. & $\% 52,02$ \\
Berber ve Balık, 2006 & Manyas Gölü & $\% 27,82$ \\
Yüksel, 2007 & Keban Baraj G. & $\% 64,4$ \\
Güner, 2008 & Kavaklı Göleti & $\% 87,75($ đ), \%93,75(†) \\
Bu çalışmada & Eğirdir Gölü & $\% 68,04$ \\
\hline \hline
\end{tabular}

Kerevitlerde boy ile ağırlık arasındaki ilişkinin, ekonomik olarak işletilen populasyonlar açısından bilinmesi gereklidir. Regresyon denklemleri özellikle populasyonun, kondüsyon, büyüme ve gelişme, eşeysel olgunluk ve farklı bölgelerdeki populasyonların karşılaştırılmasında kullanılmaktadır. Regresyon analizinden elde edilen "b değeri" organizmanın allometrik veya isometrik büyümesini göstermektedir. Eğer "b değeri" 3'ten büyük ise organizma pozitif allometrik büyüme göstermekte, eğer "b değeri" 3 'e eşit ise organizma isometrik büyüme göstermektedir (Romaire vd., 1977).

Bu çalışmada önceki araştırmalara paralel olarak karapaks ile vücut ağırlığı arasında doğrusal bir ilişki olduğu tespit edilmiştir. Yapılan regresyon analizleri sonucunda elde edilen değerlere göre karapaks uzunluğu ile vücut ağırlığı arasında hem erkek $(b=2,89)$ hem de dişi $(b=2,69)$ kerevitlerde negatif allometrik ağırlık artışı saptanmıştır.

Ülkemizde yapılan bazı çalışmalarda Mogan Gölü (Tüzün, 1987), Seyhan Baraj Gölü (Çevik, 1993), Ayrancı Baraj Gölü ( Erdem ve Erdem, 1994), Eğirdir Gölü (Bolat, 1996), İznik Gölü (Erdem vd., 2001), Keban Baraj Gölü (Duman ve Pala, 1998) erkek ve dişi bireylerinde ve Sera Gölü (Erkebay, 2004), Demirköprü Baraj Gölü (Balık vd., 2005) ile Keban Baraj Gölü (Yüksel ve Duman, 2012) erkek bireylerinde pozitif allometrik büyüme tespit edilmiştir (Tablo 3).

Keban Baraj Gölü (Harlıoğlu, 1999), Eğirdir Gölü (Bolat, 2001) ve Kavaklı Göleti (Güner, 2008) erkek ve dişi bireylerde negatif allometrik büyüme, Keban Baraj Gölü (Barım, 2007) dişilerde negatif erkeklerde pozitif allometrik büyüme, Dikilitaş Göleti (Köksal vd., 2003) erkek ve dişi bireylerinde, Demirköprü Baraj Gölü (Balık vd., 2005) dişi bireylerinde, Manyas Gölü (Berber ve Balık, 2006) ve Apolyont Gölü (Berber ve Balık, 2009) erkek ve dişi bireylerinde izometrik büyüme özelliği tespit etmişlerdir .

Canlıların gelişme süresinde boyca büyümesine karşın, ağırlıkça büyüme hızının hangi oranda olacağı, genetik yapılarının etkisine bağlı olduğu gibi, besin niteliği ve miktarı gibi beslenme olanaklarının da büyük oranda etkilerinin olduğu bilinmektedir. Tüm bu etkenler kompleks bir yapı içerisinde, türün genel yapısı içinde kalmak koşuluyla, zamana ve ortama göre, populasyondan populasyona hatta aynı populasyonda bile mevsimden mevsime boy ile ağırlık arasındaki ilişkide farklı oranlarda değişikliklere neden olabilmektedir (Berber ve Balık, 2006). 
Tablo 3. Farklı çalışmalarda regresyon sabitleri ve katsayıları

\begin{tabular}{|c|c|c|c|c|}
\hline Çalışma & $\mathbf{N}$ & Eşey & b değeri & $\mathbf{R}$ \\
\hline \multirow{2}{*}{ Mogan Gölü (Karabatak ve Tüzün, 1989) } & 669 & $\sigma^{\lambda}$ & 3,1758 & - \\
\hline & 822 & 우우 & 3,0498 & - \\
\hline \multirow{2}{*}{ Seyhan Baraj Gölü (Çevik, 1993) } & 150 & $\hat{\delta} \sigma^{\lambda}$ & 3,2464 & - \\
\hline & 150 & 우우 & 3,0385 & - \\
\hline Ayrancı Baraj Gölü (Erdem ve Erdem, 1994) & 170 & $\hat{\sigma} \hat{\sigma}+q 0$ & 3,0154 & - \\
\hline \multirow{2}{*}{ Eğirdir Gölü (Kuşat ve Bolat, 1995) } & 505 & 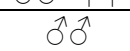 & 3,1258 & - \\
\hline & 307 & 우우 & 2,7749 & - \\
\hline \multirow{2}{*}{ Keban Baraj Gölü (Duman ve Pala, 1998) } & 257 & $\hat{\sigma}$ & 3,3772 & 0,993 \\
\hline & 177 & 우우 & 3,1462 & 0,994 \\
\hline \multirow{2}{*}{ Keban Baraj Gölü (Harlıoğlu, 1999) } & 208 & $\hat{\partial}$ & 2,6689 & 0,923 \\
\hline & 242 & 우 & 2,5152 & 0,882 \\
\hline \multirow{2}{*}{ Eğirdir Gölü (Bolat, 2001) } & 1250 & $\hat{\sigma} \hat{\sigma}$ & 2,9896 & 0,963 \\
\hline & 550 & 우우 & 2,6946 & 0,975 \\
\hline İznik Gölü (Erdem vd., 2001) & 250 & $\hat{\delta} \hat{\delta}+q$ & 3,0041 & - \\
\hline \multirow{2}{*}{ Dikilitaş Göleti (Köksal vd., 2003) } & 2122 & $\hat{\partial}$ & 3,0092 & 0,994 \\
\hline & 2298 & 우 & 3,0797 & 0,995 \\
\hline \multirow{2}{*}{ Sera Gölü (Erkebay, 2004) } & 825 & $\hat{\jmath}$ & 3,4100 & 0,975 \\
\hline & 588 & 우우 & 3,0400 & 0,975 \\
\hline \multirow{2}{*}{ Demirköprü Baraj Gölü (Balık vd., 2005) } & 233 & $\hat{0} \overline{0}$ & 3,2666 & 0,979 \\
\hline & 113 & 우운 & 3,0546 & 0,974 \\
\hline \multirow{2}{*}{ Manyas Gölü (Berber ve Balık, 2006) } & 731 & $\delta^{\lambda}$ & 2,9763 & 0,969 \\
\hline & 387 & 우운 & 2,9443 & 0,987 \\
\hline \multirow{2}{*}{ Mamasın Baraj Gölü (Büyükçapar vd., 2006) } & 356 & $\hat{O} \hat{O}^{-1}$ & 3.104 & 0.93 \\
\hline & 194 & 우우 & 2.754 & 0.86 \\
\hline \multirow{2}{*}{ Keban Baraj Gölü (Barım, 2007) } & 149 & $\hat{\sigma} \hat{o}$ & 3,2438 & 0,974 \\
\hline & 170 & 우운 & 2,8591 & 0,952 \\
\hline \multirow{2}{*}{ Keban Baraj Gölü (Yüksel ve Duman, 2012) } & 2962 & $\hat{\partial}$ & 3.0950 & 0.884 \\
\hline & 2412 & 우 & 2.7190 & 0.855 \\
\hline \multirow{2}{*}{ Bu Çalışma } & 1458 & $\hat{\partial}$ & 2,8907 & 0,911 \\
\hline & 998 & 우우 & 2,6886 & 0,888 \\
\hline
\end{tabular}

Çalışma süresince kerevitlerin kabuk durumları incelenmiş olup, Eğirdir Gölü kerevitlerinin olgunlaşma boyunun üstündeki bireylerin Mayıs ayından Kasım ayına kadar kabuk değiştirerek boy ve ağırlıkça büyüdükleri ve Ağustos-Eylül aylarında yoğun olarak kabuk değiştirdikleri belirlenmiştir.

Erdemli (1982) ve Bolat (1996) Eğirdir Gölünde farklı zamanlarda yaptıkları çalışmalarında kerevitlerin Haziran-Eylül ayları arasında kabuk değiştirdiklerini bildirmişlerdir. Duman ve Pala (1998), Keban Baraj Gölü Ağın bölgesindeki kerevitlerin kabuk değiştirme zamanlarının Haziran ayı sonlarından itibaren başlayarak Eylül ayına kadar her iki eşeyde de gerçekleştiğini gözlemlemişlerdir. Bolat (2001) Mayıs ayından Ekim ayına kadar ve yoğun olarak Ağustos-Eylül ayında kabuk değiştirmenin gerçekleştiğini belirtmiştir. Yüksel ve Duman (2012), yaptıkları araştırmada Keban Baraj Gölü kerevitlerinin Haziran-Eylül ayları arasında kabuk değiştirdikleri ve özellikle Ağustos ve Eylül aylarında kabuk değiştirme olayının daha yoğunlaştığını bildirmişlerdir. Kabuk değiştirme dönemi diğer çalışmaların bulgularıyla benzerlik göstermektedir. 
Üreme Dönemi, dişi kerevitlerin gonadları üzerinde sperma kalıntılarının görülmeye başlandığ tarih ile yumurtaların açılarak larvaların dişi bireyi terk ettiği tarih arasındaki periyot olarak kabul edilmiştir (Taugbol ve Skurdal, 1989). Çiftleşme olayının Kasım ayında gerçekleştiği, pleopodlarında yumurta taşıyan ilk dişiye Aralığın son haftasında rastlanmıştır. Yumurtalarda yavru çıkışı yaklaşık Haziranın ilk haftasında gerçekleşmiştir. Eğirdir Gölü erkek kerevitlerinin $74 \mathrm{~mm}$, dişi kerevitlerinin ise $77 \mathrm{~mm}$ 'de olgunlaştıkları belirlenmiștir.

Ülkemizde yapılan çalışmalarda olgunlaşma büyüklüğü Eğirdir Gölü erkeklerde 70 mm, dişilerde $71 \mathrm{~mm}$ (Erdemli, 1982); Mogan Gölü erkeklerde $80 \mathrm{~mm}$, dişilerde $82 \mathrm{~mm}$ (Karabatak ve Tüzün, 1989), Eğirdir Gölü erkeklerde $73 \mathrm{~mm}$, dişilerde $74 \mathrm{~mm}$ (Bolat, 1996); Seyhan Baraj Gölü erkeklerde 76 mm, dişilerde 74 mm Çevik ve Tekelioğlu,1997); Eğirdir Gölü erkeklerde $71 \mathrm{~mm}$, dişilerde $72 \mathrm{~mm}$ (Bolat, 2001), İznik Gölü dişilerde $72 \mathrm{~mm}$ (Erdem vd., 2001), Işıklı Gölü dişilerde 86,9 mm (Güner ve Balık, 2002), Demirköprü Baraj Gölü dişilerde 69-86,9 mm arasındaki total boylarda (Balık ve Ustaoğlu, 2006) tespit etmişlerdir.

Populasyondaki bireylerin yumurta verimliliği ortalama yumurta sayısı ve ortalama yumurta çapı değerlerinden hesaplanmıştır. Yumurta sayılarına bakıldığında farklı boy gruplarında düşük ve yüksek yumurta veren bireylere rastlanabilmektedir. Literatürde $A$. leptodactylus türünün ortalama 200 ile 400 adet arasında yumurta ürettiği bildirilmektedir (Erdemli, 1985). Ülkemizde yumurta sayıları ile ilgili yapılan araştırmalarda ortalama yumurta sayıları; Eğirdir Gölünde ortalama 170 (Anonymous, 1980); Eğirdir Gölü'nde 148, Beyşehir Gölü'nde 156, Akşehir Gölü'nde 149, Eber Gölü'nde 161, Apa Baraj Gölü'nde 153; Mamasın Gölü'nde 158, Hotamış Gölü'nde 163 (Erdemli, 1985); Mogan Gölü'nde 175; (Karabatak ve Tüzün, 1989); Seyhan Baraj Gölünde 171(Çevik, 1993); Eğirdir Gölü’nde 277 (Bolat,1996); Keban Baraj Gölü’nde 97-289 (Duman ve Gürel, 2000); İznik Gölünde ortalama 154 (Erdem vd., 2001); Işıklı Gölü'nde 216 (Güner ve Balık, 2002); Demirköprü Baraj Gölü’nde 137 (Balık vd., 2006); Bafra Balık Gölleri'nden Ulugöl'de 178 adet (Uzun vd., 2013) olduğunu ifade etmişlerdir. Çalışmada, Aralık-Haziran ayları arasında avlanan kerevitlerin ortalama yumurta sayısı 309 adet olarak belirlenmiş ve diğer çalışmalarda elde edilen değerlerden yüksek bulunmuştur.

Kerevitlerin yumurta çaplarının 2-3 mm arasında değiştiği, yumurta çapları ile ilgili yapılan çalışmalarda; Eğirdir Gölü için 2,49 mm, Beyşehir Gölü için 2,44 mm, Akşehir Gölü için 2,47 mm, Eber Gölü için 2,43 mm, Apa Baraj Gölü için 2,5 mm (Erdemli, 1983); Hotamış Gölü için 2,43 mm, Mamasın Baraj Gölü için 2,48 mm (Erdemli, 1985); Seyhan Baraj Gölü için 2,52 mm (Çevik;1993); Keban Baraj Gölü Ağın Bölgesi için 2,88-3,03 mm (Duman ve Gürel, 2000); İznik Gölü için 2,5 mm (Erdem vd., 2001); Eğirdir Gölü için 2,77 mm (Bolat, 2001); Işıklı Gölü için 2,45 mm (Güner ve Balık, 2002); Demirköprü Baraj Gölü için 2,72 mm (Balık vd., 2006); Bafra Balık Gölleri'nden Ulugöl'de 2,11 mm (Uzun vd., 2013) olarak tespit etmişlerdir. Çalışmada örnek populasyondan elde edilen ortalama yumurta çapının $2,53 \mathrm{~mm}$ olduğu belirlenmiş olup, diğer çalışmalardaki değerlerin bir kısmından düşük bir kısmından ise büyük olduğu belirlenmiştir.

Tatlısu istakozları ile ilgili yapılan çalışmalarda yumurta büyüklüğü üzerinde parazitlik, predatör baskıs1, su kalitesi, beslenme gibi çevresel faktörlerin etkisinin olduğu (Corey, 1991; Huner ve Lindqvist, 1991) ve dişi kerevitin total ağırlık, karapaks boyu ile yumurta büyüklüğü ve ağırlığı arasında bir bağlantının olmadığı bildirilmektedir (Harlıoğlu ve Türkgülü, 2000; Güner ve Balık, 2002; Uzun vd., 2013). Yumurta verimliliğinin ekolojik faktörlerden daha çok genetik faktörlerce kontrol edildiği belirtilmektedir (Erdemli, 1985). 
Sonuç olarak; Eğirdir Gölü kerevitlerinin üreme ve büyüme özellikleri bakımından daha önce yapılan çalışmalarla karşılaştırıldıklarında normal biyolojik özelliklerini korudukları ve bu döngüde herhangi bir sapmanın olmadığı tespit edilmiştir.

Teşekkür: $\mathrm{Bu}$ çalışmayı destekleyen Süleyman Demirel Üniversitesi Bilimsel Araştırma Projeleri Yönetim Birimi’ne teşekkür ederiz (Proje No:3532-YL1-13).

\section{Alıntılama}

Bolat Y., Kaya M. A.2016. Eğirdir Gölü kerevitlerinde (Astacus leptodactylus, Eschscholtz, 1823) büyüme ve üreme özelliklerinin belirlenmesi. Eğirdir Su Ürünleri Fakültesi Dergisi. 12(1), 11-24.

\section{KAYNAKLAR}

Adegboye, D., 1981 The "Crayfish Condition Factor" a tool in crayfish research, International Symposium on Freshwater Crayfish ( 5. 1981: Davis, Claif.) The Avi Publishing Company, Inc. Westport, Connecticut.

Anonymous, 1980. Investigation of reproduction and population of crayfish in Eğirdir Lake, Su Ürünleri Genel Müdürlüğü, Isparta Su Ürünleri Bölge Müdürlüğü Yayınları, Yayın No: 2, Isparta.

Atay, D., 1989. Populasyon Dinamigi, Ankara Üniversitesi Ziraat Fak. Yayınları Ders Kitabı, No:324, $306 \mathrm{~s}$.

Balık, S. Usataoğlu, M.R., Sarı, M.H., Berber, S., 2005. Demirköprü Baraj Gölü (Manisa) Tatlısu Istakozu (Astacus leptodactylus, Eschscholtz, 1823)'nun Bazı Büyüme ve Morfometrik Özelliklerinin Belirlenmes., Ege Üniversitesi Su Ürünleri Dergisi 22(1-2),83-89.

Balık, S. Usataoğlu, M.R., Sarı, M.H., Berber, S., 2006. Demirköprü Baraj Gölü (Manisa) Tatlısu Istakozu (Astacus leptodactylus, Eschscholtz, 1823)'nun Bazı Üreme Özellikleri. Ege Üniversitesi Su Ürünleri Dergisi 23(3-4), 245-249.

Barım, Ö., 2007. Keban Baraj Gölü, Çemişgezek Bölgesi Tatlı Su Istakozu, Astacus leptodactylus Eschscholtz, 1823'un Morfometrik Analizi ve Et verimi. Science and Eng. J of Firat Üniversitesi 19(3), 301-307.

Berber, S., Balık, S., 2006. Manyas gölü (Balıkesir) tatlısu istakozunun (Astacua leptodactylus, Eschscholtz, 1823) bazı büyüme ve morfometrik özelliklerinin belirlenmesi. Ege Üniversitesi Su Ürün Dergisi 23(1-2), 83-91.

Berber, S., Balık, S., 2009. Apolyont Gölü (Bursa-Türkiye) Tatlısu İstakozunun (Astacus Leptodactylus Eschscholtz, 1823) Boy-Ağırlık İlişkisi ve Et verimi. Journal of FisheriesSciences.com, 3(2), 86-99.

Bolat, Y., 1996. Eğirdir Gölündeki Kerevit (Astacus leptodactylus salinus Eschschotz, 1842)Popülâsyonunun Bazı Özellikleri ve Hastalığının Morfolojik İncelenmesi. Süleyman Demirel Üniversitesi, Fen Bilimleri Enstitüsü, Yüksek Lisans Tezi, Isparta.

Bolat, Y., 2001. Eğirdir Gölü Tatlı Su İstakozlarının Populasyon Büyüklüğünün Tahmini. Süleyman Demirel Üniversitesi, Fen Bilimleri Enstitüsü, Doktora Tezi, Isparta.

Büyükçapar, H. M., Alp, A., Kaya, M., Çiçek, Y., 2006. Mamasın Baraj Gölü (Aksaray-Türkiye) Tatlısu İstakozu (Astacus leptodactylus Eschscholtz, 1823)'nun Boy-Ağırlık İlişkisi ve Et Verimi. Ege Üniversitesi Su Ürünleri Dergisi 23(1-2), 21-25.

Corey, S., 1991. Comparative potential reproduction and actual production in several species of North American crayfish. In: Wenner, A., Kuris, A. (Eds.), Crustacean Egg Production, Crustacean Issues, vol. 7, Rotterdam, 69-76.

Çevik, C., 1993. Seyhan Baraj Gölünde Yaşayan Tatlısu İstakozu (Astacus leptodactylus, Eschscholtz, 1823)'nun Bazı Biyo-Ekolojik, Morfometrik Özellikleri ile Hastalık Durumunun Saptanması. Çukurova Üniversitesi. Fen Bilimleri Enstitüsü, Su Ürünleri Anabilim Dalı, Yüksek Lisans Tezi, 40s, Adana. 
Çevik, C., Tekelioğlu, N., 1997. Seyhan Baraj Gölünde Yaşayan Tatlısu Istakozu (Astacus leptodactylus, Esch., 1823)'nun Bazı Biyo-Ekolojik, Morfometrik Özellikleri ile Hastalık Durumunun Saptanmas1, IX. Su Ürünleri Sempozyumu, Eğirdir/Isparta, 1, 270-279.

Duman, E., Pala, M., 1998. Keban Baraj Gölü Ağın Bölgesinde Yaşayan Kerevit (Astacus leptodactylus salinus Nordmann, 1842) Populasyonunun Büyüme Özelliklerinin İncelenmesi. Ege Üniversitesi Su Ürünleri Dergisi, 15(1-2), 9-17.

Duman, E. Gürel, A., 2000. Keban Baraj Gölü Ağın Bölgesi'nde Yaşayan Kerevitin (Astacus leptodactylus salinus Nordmann, 1842) Üreme Özelliklerinin Belirlenmesi. Doğu Anadolu Bölgesi IV. Su Ürünleri Sempozyumu, 141-150.

Erdem, U., Erdem Ü., 1994. Ayrancı baraj gölündeki (Karaman) Tatlısu istakozu (Astacus leptodacytlus Esch. 1823)'nun bazı ekolojik ve morfometrik özelliklerinin incelenmesi, XII. Ulusal Biyoloji Kongresi, Hidrobiyoloji Seksiyonu, 358-360, Edirne.

Erdem, Ü., Cebeci, M., Selçuk, S., Tunç, N., Özbay, A. Ve Çildem, B., 2001. İznik Gölü'ndeki Tatlısu Istakozu (Astacus leptodactylus Eschscholtz, 1823)'nun Bazı Biyo-Ekolojik Özelliklerinin İncelenmesi. XI. Ulusal Su Ürünleri Sempozyumu, 04-06 Eylül, Hatay, 449-456.

Erdemli, A. Ü., 1982. Beyşehir, Eğridir, Akşehir ve Eber Gölleriyle Apa Baraj Gölü Tatlısu İstakozu (Astacus leptodactylus Esch., 1823) Populasyonları Üzerine Karşılaştırmalı Bir Araştırma, Doğa Bilim Dergisi: Veterinerlik ve Hayvanc1lık, 313-318.

Erdemli, A. Ü., 1985. Hotamış gölü ve Mamasın baraj gölünde tatlısu istakozu (Astacus leptodactylus salinus Nordmann, 1842) populasyonlarının bazı biyolojik ve morfolojik özelikleri üzerine bir araştırma. Türkiye Bilimsel Araştırma Kurumu Matematik, Fizik ve Biyoloji Araştırma Grubu, Proje No: TBAG 594, 73s.

Erkebay, C., 2004. Sera Gölü (Trabzon) Kerevit (Astacus leptodactylus, Esc, 1828) Stoğunun Biyolojik Özellikleri, Stok Yapısı ve Doğu Karadeniz Şartlarında Yetiştiricilik olanakları, Karadeniz Teknik Üniversitesi Fen Bilimleri Enstitüsü, Balıkçılık Teknolojisi Mühendisliği Anabilim Dalı, Doktora Tezi, 70.

Geldiay, R., Kocataş A., 1970. Taxonomical Determination and Distribution of Turkish Astacus (Decapoda) Populations (In Turkish). Ege Üniversitesi Fen Fakültesi İlmi Raporlar Serisi 94,3-7.

Güner, U., 2000. Some Biologic properties of Crayfish (Astacus leptodactylus Eschscholtz, 1823) in Işıklı Lake (Denizli). Ege Üniversitesi, Fen Bilimleri Enstitüsü, Su Ürünleri Temel Bilimler A.B.D. Yüksek Lisans Tezi, $65 \mathrm{~s}$.

Güner, U., Balık, S., 2002. Işıklı Gölü (Çivril-Denizli) Tatlı su Kerevitlerinde (Astacus leptodactylus Esch., 1823) Yumurta Verimliğinin Boy ve Ağırlıkla İlişkisi. Ege Üniversitesi Su Ürünleri Dergisi 19(1/2), 109-113.

Güner, U., 2008. Kavaklı Göleti (Edirne-Meriç) Kerevitleri Astacus Leptodactylus (Eschscholtz, 1823)'un Bazı Morfolojik Özellikleri İle Büyüme Parametreleri, Biyoloji Bilimleri Araştırma Dergisi (BIBBAD).1(1), 37-42.

Harlığlu, M, M., 1999. Keban Baraj Gölü Ağın Yöresi Tatlı Su İstakozu, (Astacus leptodactylus Eschscholtz) Populasyonunda Ağırlık-Uzunluk İlişkisi ve Et Verimi, Tr. J. Zoology 23 (1999) Eksayı 3, 949-957.

Harlığlu, M.,M., 2000. The relationship between egg size and female size in freshwater crayfish, Astcaus leptodactylus, Aquaculture International 8, 95-98.

Harlığlu, M.M. ve Türkgülü, İ., 2000. The relationship between egg size and female size in freshwater crayfish, (Astacus leptodactylus Eschscholtz, 1823), Aquaculture International, 8,95-98.

Harlığlu, M.M., Harlığlu, A.G., 2005. Eğirdir, İznik Gölleri ve Hirfanlı Baraj Gölünden avlanan tatlı su istakozu Astacus leptodactylus (Eschscholtz, 1823)'un morfometrik analizleri ile et verimlerinin karşılaştırılması. Fırat Üniversitesi Fen ve Mühendislik Bilimleri Dergisi 17(2), 412-423. 
Hessen, D.O., Kristiansen, G., Skurdal, J., 1993. Nutrient Release From Crayfish, and Its Potential Impact on Primary Production in Lakes, Freshwater Crayfish, 9, 311-317.

Hogger, J.B., 1988. Ecology, population biology and behaviour, Freshwater crayfish: Biology, Management and Exploitation (Eds. Holdich, D.M.; Lowery, R.S.), Chapman \& Hall, London, 114-144.

Huner, J. V. and Lindqvist, O. V., 1991. Special problems in freshwater crayfish egg production. In: Crustacean Egg Production, Vol. 7 (eds. A. Wenner and A. Kuris), Crustacean Issues, A.A. Balkema, P.O. Box 1675, 3000 BR Rotterdam, pp. 235-246.

Huner, J.V., 1994. Freshwater Crayfish Aquaculture in North America, Europe, and Australia: Families Astacidae, Cambaridae, and Parastacidae, Food Products Press, New York, USA, 312s.

Karabatak, M., Tüzün, İ., 1989. Mogan gölündeki kerevit (Astacus leptodactylus, Esch, 1823) populasyonun bazı özellikleri, Akdeniz Üniversitesi Su Ürünleri Mühendisliği Dergisi 2, 1 34.

Köksal, G. (1980). Biometric analysis on the freshwater crayfish (Astacus leptodactylus, Esch., 1823) Which is produced in Turkey, relationship between the major body components and meat yield. Ank. Üniv., Veteriner Fak., Derg., C : XXVI (3-4), 93-114.

Köksal, G., 1988. Astacus leptodactylus in Europe. Freshwater Crayfish Biology, Management and Exploitation (Eds. Holdich, D.M.; Lowery, R.S.), Croom Helm, London, 365-400.

Köksal, G., Korkmaz, A.Ş. ve Kırkağaç, M., 2003. Ankara-Dikilitaş Göleti Tatlı Su İstakozu (Astacus leptodactylus, Esch., 1823) Populasyonunun İncelenmesi. Tarım Bilimleri Dergisi, ss: $51-58$.

Kuşat, M., Bolat, Y., 1995. Eğirdir Gölü Tatlısu İstakozu (Astacus leptodactylus, Esch., 1823)'nun Boy-Ağırlık Dağılışı ve Kerevit Vebası Hastalığının İncelenmesi. Ege Üniversitesi Su Ürünleri Dergisi 12(1-2), 69-74.

Le Cren, E.D. (1951). The Length-Weight Relationship and Seasonal Cycle in Gonad Weight and Condition in the Perch (Perca fluviatilis). J. Anim. Ecol. Cambrige 20, 201-219.

Matthews, M., Reynolds, J.D., 1992. Ecological impact of crayfish plague in Ireland, Hydrobiologia, 234, 1-6.

Momot, W.T., 1995. Redefining the role of crayfish in aquatic ecosystems, Reviews in Fisheries Science, 3, 33-63.

Nyström, P., Strand, J.A., 1996. Grazing by a native and an exotic crayfish on aquatic macrophytes, Freshwater Biology, 36, 673-682.

Nyström, P., 2002. Ecology. Biology of Freshwater Crayfish (Ed. Holdich, D.M.), Blackwell Scientific, Oxford, 192-235.

Reynolds, J.D., J.D. Celada, J.M. Carral. and M.A. Matthews. 1992. Reproduction of astacid crayfish in captivity-current developments and implication for culture, with special reference to Ireland and Spain. Invertebr. Reprod. Dev. 22(1-3), 253-266.

Romaire, R.P., Forester J.S. and Avault, J.V., 1977. Length-weight relationships of two commercially important crayfishes of the genus Procambarus. Freshwater Crayfish 3, 463470.

Taugbol, T., Skurdal, J. (1989). Effect of indoor, culture conditions on maturation and fecundity of wild-caught female noble crayfish, Astacus astacus, Aquaculture, 81, 1-12.

Tüzün, İ., 1987. Mogan Gölü'ndeki Kerevit (Astacus leptodactylus Eschscholtz, 1823)'in Biyolojisi Ankara Üniversitesi, Fen Bilimleri Enstitüsü Biyoloji Anabilim Dalý Yüksek Lisans Tezi, $48 \mathrm{~s}$.

Uzun, G., Baki, B., Baki, B., Karayücel, S., 2013. Bafra Balık Gölleri'nden Ulugöl'de Tatlısu Istakozu (Astacus leptodactylus Eschscholtz, 1823)'nun Yumurta Verimliliği. Yunus Araştırma Bülteni, 2013(1), 20-26.

Wallace, J.B., Eggert, S.L., Meyer, J.L., Webster, J.R., 1997. Multiple trophic levels of a forest stream linked to terrestrial litter inputs, Science, 277, 102-104. 
Yüksel, F. 2007. Keban Baraj Gölü Kerevit (Astacus leptodactylus Eschscholtz, 1823) Populasyon Büyüklügüunün Araştırılması, Doktora Tezi, Fırat Üniversitesi, Elazı̆̆.

Yüksel, F., Duman, E., 2012. Keban Baraj Gölü Kerevitlerinin (Astacus leptodactylus Esch., 1823) Bazı Morfolojik Özelliklerinin İncelenmesi. Journal of FisheriesSciences. com, 6(4), 271 281.

Zhang, Y., Negishi, J.N., Richardson, J.S., Kolodziejczyk, R., 2003. Impact of marine-derived nutrients on stream ecosystem functioning, Proceedings of the Royal Society of London, Series B, 270, 2117-2123.

Zhang, Y., Rihardson, J.S., Negihi, J.N., 2004. Detritus processing, ecosystem engineering and benthic diversity: a test of predator-omnivore interference, Ecology Journal of Animal, 73, 756-766. 